Covered in: Web of Sciences (WOS); EBSCO; ERIH+; Google Scholar; Index Copernicus; Ideas RePeC; Econpapers; Socionet; CEEOL; Ulrich ProQuest; Cabell, Journalseek; Scipio; Philpapers; SHERPA/RoMEO repositories; KVK; WorldCat; CrossRef; CrossCheck

2018, Volume 10, Issue 1, pages: 107-120 | doi: https://doi.org/10.18662/rrem/22

\section{Learning the Swimming Start by Students in Higher Education of other Profiles}

\author{
Elena - Diana SIMA ${ }^{1}$, \\ Vladimir POTOP $^{2} *$
}

1 „Carol Davila” University of Medicine and Pharmacy of Bucharest, Romania, dianasima@yahoo.com

${ }^{2}$ Faculty of Physical Education and Sport, Ecological University of Bucharest, Romania, vladimir potop@yahoo.com

\begin{abstract}
This paper aims to highlight how to use the computerized video analysis for learning the sports technique key elements of the start in swimming in the case of the students in higher education of other profiles. This scientific approach entailed the organization of an ascertaining experimental study, using the following research methods: bibliographic study of the specialized literature, video computerized method by means of Pinnacle Studio, Kinovea and Physics ToolKit programs, method of movement postural orientation, statistical-mathematical method which uses the KyPlot program and the method of graphical representation of results. The research was conducted from October 2017 to January 2018 and included 12 students (second-year - series no. 2) of the Faculty of General Medicine. The results of the study show the muscle strength development of arms, abdomen and legs of the students under research. The use of the video computerized method highlights and identifies the kinematic and dynamic characteristics of sports technique key elements used in swimming start regarding the launching posture, multiplication of body posture (flying through the air) and concluding body posture (entering the water). The propulsion and going out of water will be studied depending on the specific swimming style chosen by the students. The effective use of the computerized video analysis that deepens the understanding of sports technique phasic structure will allow the processing of the modern didactical programs for swimming learning. The modern research methods used in the video computerized analysis of sports technique of the start in swimming are an important help for the measurement, analysis and evaluation of the kinematic and dynamic structure of all swimming styles.
\end{abstract}

Keywords: Swimming; biomechanics; key elements; physical training; performance.

How to cite: Sima, E.-D., \& Potop, V. (2018). Learning the Swimming Start by Students in Higher Education of other Profiles. Revista Romaneasca pentru Educatie Multidimensionala, 10(1), 107-120. https://doi.org/10.18662/rrem/22 


\section{Introduction}

People generally are interested in swimming practice, thus in the academic environment too more and more students choose the swimming for their physical education classes. It was found out that a revision of physical education concept is needed (Urichianu-Toma, 2004).

In this respect E. Lupu (Lupu, 2009) proposes the necessity to revise the concept on physical education and test events in the higher education of other profiles in order to practice swimming in university environment and at different ages as well; its multiple influences upon the body, especially in the growth period, and its utilitarian-applicative character are the main arguments that give this branch of sport a special place in the concept of training of the young generation (Urichianu-Toma, 2003), (Sima, 2011).

The practice of physical education in the higher education of other profiles is essentially connected with the examination of the objectives and competencies provided by this field, the quality of students' motivation, the diversity of practicing forms and also the evaluation strategies of the training activity from the perspective of the roles and competencies of the teaching staff (Ionescu, 2009).

The specialized methods-scientific literature focuses especially on the learning of swimming and of other elements of swimming technical procedures, such as the starts and turns. These important elements of swimmers' competitive activity are consolidated and governed by the Fédération Internationale de Natation - FINA (International Swimming Federation). The theory and methods of swimming teaching in the faculties of physical education and sport and in the departments of physical education and sport belonging to the faculties of other profiles still lack of enough teaching aids well substantiated and scientifically processed, meant to support the physical education and sport subject matter or even the swimming (Ganchar, 2006).

The activity of physical education and sport in higher education is an integral part of the instructive-educational program which has as main goal the harmonious physical and mental development and the education of the personality traits of the individual. This activity is carried out through several forms of organization. If the students practice a program of physical exercises systematically, they will get to know the benefic effects of sports and will be interested in sport generally or in different branches of sport (Voinea, Iacobini, \& Iacobini, 2013). 
During the training process, in addition to the exercises for strengthening and improvement of the motor skills and abilities which are dominant in the swimming styles accessible to the students (front crawl, breaststroke and backstroke), there will be also used exercises for learning the starts and the returns (Marinescu \& Balan, 2007).

There are also many studies on the biomechanical analysis in swimming that contribute to the deeper knowledge of the procedures (styles) technique regarding the musculoskeletal modelling in sports evaluation of different software tools with focus on swimming; front crawl swimming analysis using accelerometers: a preliminary comparison between pool and flume; improvement of crawl stroke for the swimming humanoid robot to establish an experimental platform for swimming research; Interanalyst variability in swimming competition analysis; the effect of swimsuit resistance on freestyle swimming race time etc. (Hudson, 2014), (Nakashima \& Tsunoda, 2015; Nordsborg, Espinosa, David, \& Thiel, 2014; Webb, Taunton, Hudson, Forrester, \& Turnock, 2014),(Langholza, Westmana, \& Karlsteen, 2016), (Espinosa, Nordsborg, \& Thiel, 2015; Hunea et al., 2017; Platonov, Absaljamov, Bulatova, \& Bulgakova, 2000).

This paper aims to highlight how to use the computerized video analysis for learning the sports technique key elements of the start in swimming in the case of the students in higher education of other profiles.

Hypothesis of the research: we believe that by applying the computerized video method in learning the start in swimming for the higher education students in accordance with their physical training level will highlight the kinematic and dynamic characteristics of sports technique key elements necessary for a more efficient development of the modern didactical programs of learning and improving the movement in aquatic environment in the chosen swimming styles.

\section{Methodology}

This scientific approach entailed the organization of an ascertaining experimental study, using the following research methods: video computerized method based on the following programs (Pinnacle Studio, Kinovea and Physics ToolKit), method of movement postural orientation (Boloban, 2013), (Potop, 2015), statistical-mathematical method of data analysis using KyPlot program and the method of graphical representation of the results. 
The research was carried out from October 2017 to January 2018 and involved the participation of 12 students of second-year $\left(1^{\text {st }}\right.$ semester, series 2) of the Faculty of General Medicine.

A number of three test events were applied during the swimming lessons: 1) abdominal strength evaluated by torso raises from supine position in $30 \mathrm{sec}$. (no of reps); 2) arms strength evaluated by push-ups executed continuously (no of reps) and 3) legs strength evaluated by jumping squats in $30 \mathrm{sec}$. (no of reps).

With regard to the structure of the swimming lesson in the off-water training, we used exercises for the selective influence of the loco-motor system (warm-up exercises) and exercises for the development of the muscle power (test events). The on-water training included exercises for learning and improving the start.

The following experimental variables were used in this study: tests events for physical training evaluation; anthropometrical and biomechanical indicators necessary for the biomechanical analysis; angular characteristics of the start technique key elements; performances achieved in competitions.

The analysis was based on the phasic structure of the start key elements in swimming and used the method of postural orientation of the movement in space:

1) Preparatory phase - launching posture (start) - LP - before beginning the movement of diving off the starting block;

2) Basic phase - multiplication of body posture (MP) - flying phase;

3) Final phase - concluding posture for entering the water (CP).

The biomechanical analysis was made by means of Kinovea program for measuring the angular characteristics of the technique key elements in the phasic structure of the start (fig. 1) and also the Physics ToolKit program for the assessment of the kinematic and dynamic characteristics of the start at swimming (fig. 2).

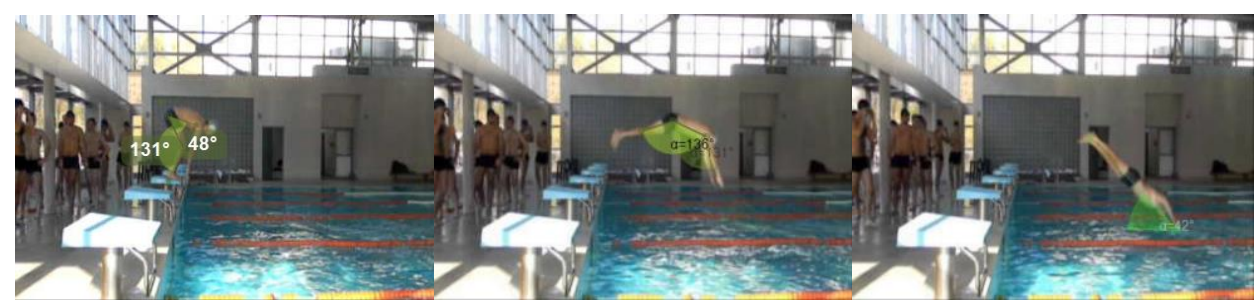

Fig. 1. Program for measuring the angular characteristics of the key elements of the standing start technique in swimming (Kinovea) 


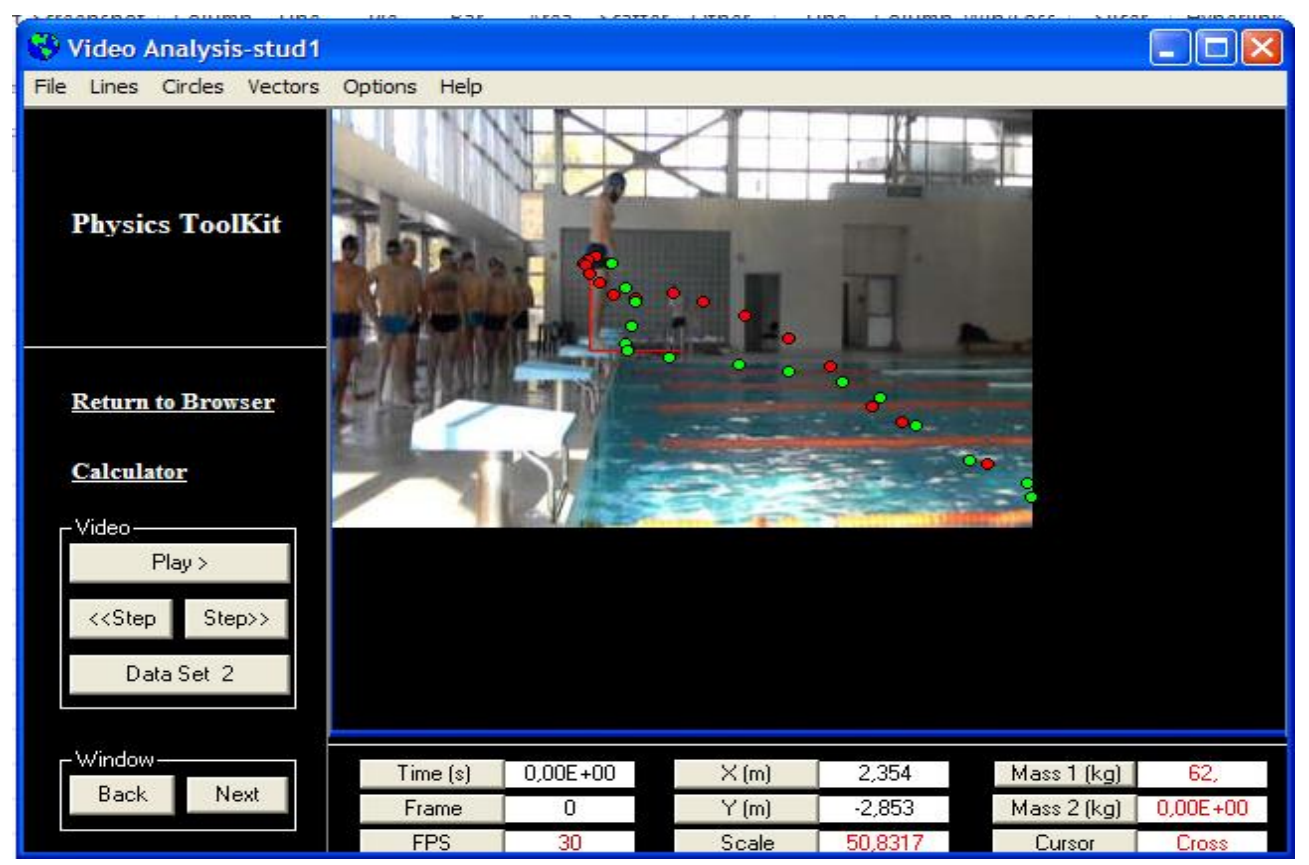

Fig. 2. Program of video biomechanical analysis of the start in swimming (Physics ToolKit)

\section{Results}

The level of physical training of the subjects of the study was evaluated by means of the test events included in the university curriculum of the higher education of other profiles within the "Carol Davila" University of Medicine and Pharmacy of Bucharest.

Table 1 shows the results of the test events of second-year students regarding abdominal strength, arms strength, legs strength and performances during the examination lesson.

Table 1. Results of students' test events $(n=12)$

\begin{tabular}{ccccc}
\hline $\begin{array}{c}\text { Statistical } \\
\text { indicators }\end{array}$ & $\begin{array}{c}\text { Abd.F } \\
\text { Torso raise, } \\
\text { NO }\end{array}$ & $\begin{array}{c}\text { BrF } \\
\text { pushups } \\
\text { NO }\end{array}$ & $\begin{array}{c}\text { Pic F. } \\
\text { Jump squats, } \\
\text { NO }\end{array}$ & $\begin{array}{c}\text { Perf. } \\
\text { crawl, } \\
\text { sec }\end{array}$ \\
\hline Mean & 25.75 & 22.08 & 23.75 & 42.80 \\
S.E.M. & 0.96 & 1.14 & 0.73 & 1.96 \\
S.D. & 3.33 & 3.94 & 2.53 & 6.79 \\
Cv $\%$ & 12.95 & 17.85 & 10.64 & 15.88
\end{tabular}

Note: S.E.M. - standard error mean, S.D.- standard deviation, $\mathrm{Cv}$ - coefficient of variation; F. strength, abd. - abdomen, Br. - arms (upper limbs), Pic. - legs (lower limbs), Perf. - performance, $\mathrm{NO}$ - reps number. 
In table 2 are listed the results of the anthropometrical and biomechanical indicators necessary for the analysis of the kinematic and dynamic characteristics of swimming start technique. The indicators present the subjects' height and weight, the inertia of the specific rotation of the translation movement with rotation around GCG and the movement radius of body segments (foot, shoulder and palm).

Table 2. Results of anthropometric and biomechanical indicators necessary for technique analysis $(\mathrm{n}=12)$

\begin{tabular}{ccccccc}
\hline $\begin{array}{c}\text { Statistical } \\
\text { indicators }\end{array}$ & $\begin{array}{c}\text { Height, Weight, IR, } \mathrm{kg} \cdot \mathrm{m}^{2} \\
\mathrm{~m}\end{array}$ & $\begin{array}{c}\text { RM, } \mathrm{m} \\
\mathrm{m}\end{array}$ & $\begin{array}{c}\text { Foot } \\
\text { shoulders }\end{array}$ & palm \\
\hline Mean & 1.78 & 69.50 & 27.68 & 0.82 & 0.511 & 0.716 \\
& 1 & & & & & \\
S.E.M. & 0.02 & 2.35 & 1.37 & 0.03 & 0.01 & 0.03 \\
S.D. & 0.06 & 8.13 & 4.75 & 0.09 & 0.05 & 0.09 \\
Cv $\%$ & 3.41 & 11.69 & 17.15 & 11.02 & 10.07 & 13.59 \\
\hline
\end{tabular}

Note: table 1; IR - inertia of rotation, RM - radius of movement

Table 3 presents the results of the angular characteristics of the key elements of standing start technique on the standing block for the swimming styles (freestyle, breaststroke and butterfly) measured with Kinovea program in terms of angle between shank and hip and the angle between hip and torso in the launching posture (start) - LP; angle between hip and torso and angle between torso and arms in the multiplication of the posture (MP) in the flight phase and the angle between water horizontal line and body longitudinal line.

Table 3. Results of angular characteristics of the key elements of start technique in swimming $(\mathrm{n}=12)$

\begin{tabular}{cccccc}
\hline $\begin{array}{c}\text { Statistical } \\
\text { indicators }\end{array}$ & \multicolumn{2}{c}{ LP, degrees } & \multicolumn{2}{c}{ MP, degrees } & CP, degrees \\
Gb-Cs & Cs-Tr & Cs-Tr & Tr- B & horiz.-foot \\
\hline Mean & 127 & 62 & 125 & 143.92 & 36.92 \\
S.E.M. & 4.28 & 7.41 & 5.44 & 4.74 & 2.28 \\
S.D. & 14.84 & 25.67 & 18.84 & 16.42 & 7.89 \\
Cv $\%$ & 11.68 & 41.41 & 15.07 & 11.41 & 21.37 \\
\hline
\end{tabular}

Note: table 1; LP - launching posture (start position) - angle between shank and hip (Gb-Cs) and between hip and torso (Cs-Tr), MP - multiplication of body posture- angle between hip and torso, $\mathrm{CP}$ - concluding posture (entering the water) - angle between the water horizontal line (horiz.) and the longitudinal line of the body

Figure 3 shows the spatial characteristics of body segments in the subject stud4 (results archives), regarding the trajectories of the foot, GCG, 
shoulder and palm of each key element within the phasic structure of this one.

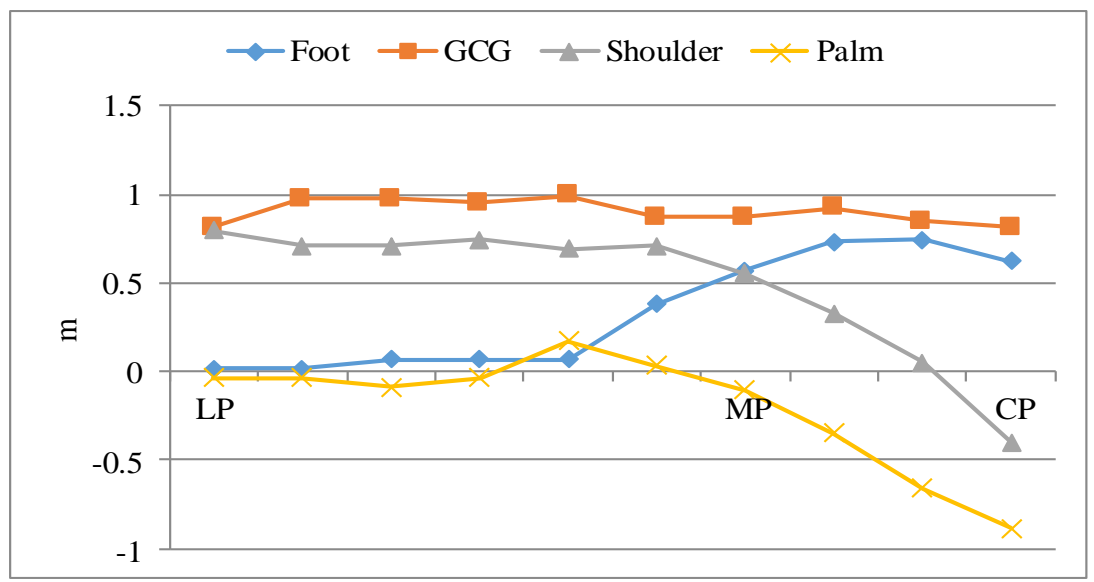

Fig. 3. Trajectories of body segments in standing start (example - stud4)

Figure 4 shows the results of the angular velocity of body segments during the execution of the standing start by the subject stud4, regarding the values of the relation between the translation movement with rotation around GCG and foot, shoulder and palm.

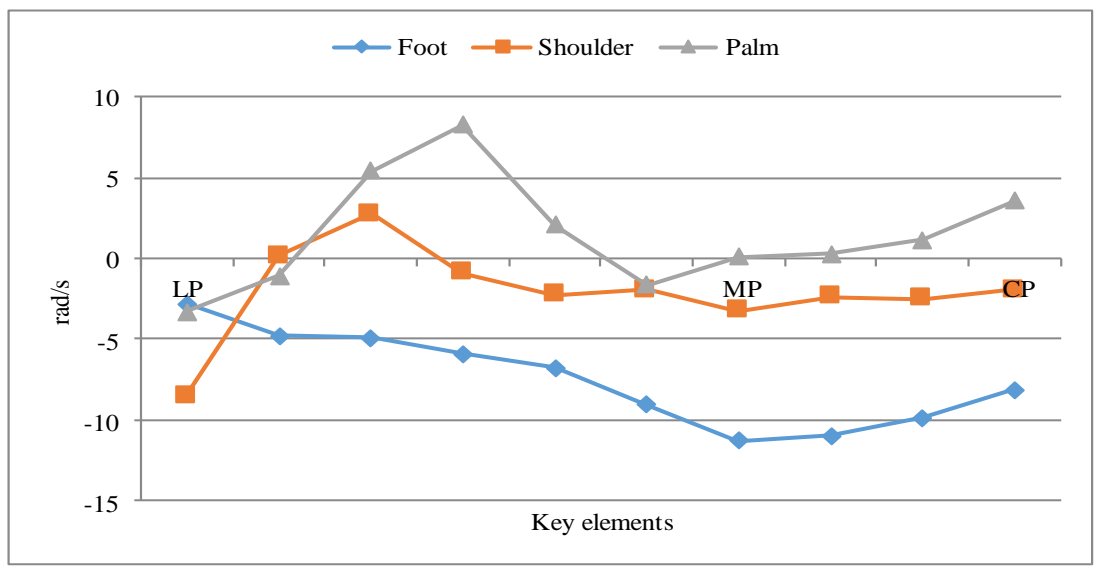

Fig. 4. Angular velocity of body segments while executing the standing start (example - stud4)

Figure 5 presents the results of displacement force of GCG in the execution of the standing start by the subject stud4, regarding the horizontal force $(\mathrm{Fx})$, vertical force $(\mathrm{Fy})$ and the resultant of force $(\mathrm{F})$ during the phasic structure of this one. 


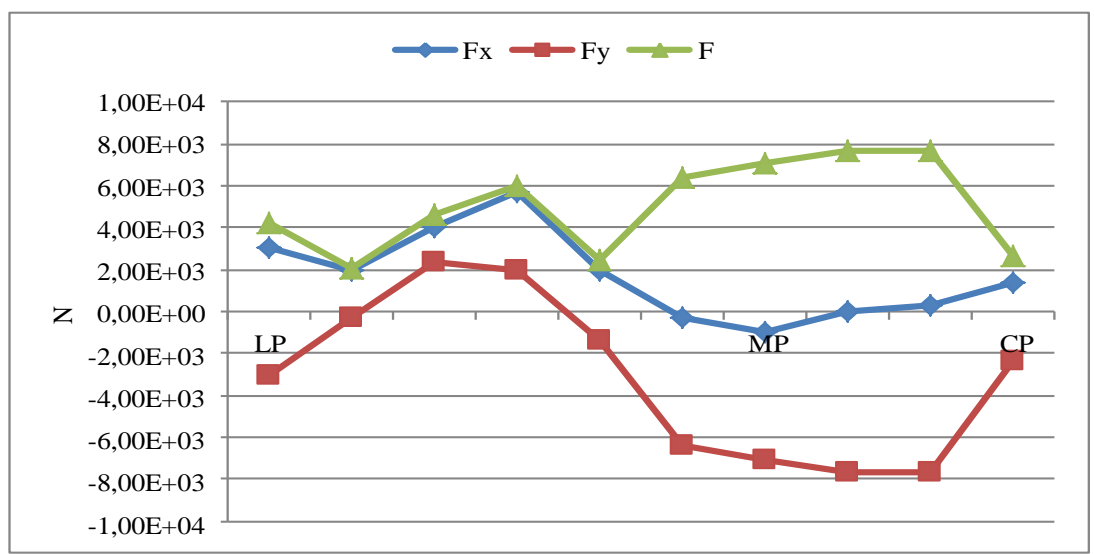

Fig. 5. Force of GCG displacement in the execution of the standing start (example - stud4)

Table 4 shows the results of the correlation between the angular characteristics of the key elements of start technique in swimming, the level of physical training and the performances achieved in the lesson of verification.

Table 4. Results of the correlation between the angular characteristics of the key elements of start technique in swimming, the level of physical training and the performances achieved in the verification lesson

\begin{tabular}{cccccc}
\hline r - Pearson & \multicolumn{2}{c}{ LP, degrees } & \multicolumn{2}{c}{ MP, degrees } & CP, degrees \\
& Gb-Cs & Cs-Tr & Cs-Tr & Tr- B & horiz.-foot \\
\hline Abd.F & -.107 & .294 & -.292 & -.366 & $*_{-} .637$ \\
Br. F & .101 & .296 & -.246 & -.312 & $* *_{-} .742$ \\
Pic F. & .262 & -.101 & -.017 & .484 & -.448 \\
Perf. & .398 & .055 & $* * .734$ & -.497 & .266 \\
\hline
\end{tabular}

Notes: tables 1 and 3, r- Pearson's parametric linear correlation test, ${ }^{*}-\mathrm{p}<0.05,{ }^{*}-\mathrm{p}<0.01$

\section{Discussions}

After the analysis of the specialized literature we noticed the following particularities of the swimming start: more efficient technique of start execution ((Parfenov, Pasichnichenko, Ivanchenko, \& Parfenova, 1990)), increase of initial velocity and flight (Nyvandi, 1963), different variants of positions used in the initial posture (Polevoj \& Ruvinskij, 1972),(Schramm, 1987), improvement of the start 2 or 3 months ahead the official competitions (Bazhanov \& Melkonov, 1979) use of arms circular swing by the swimmers with good spring while the swimmers with poor 
spring grasp the edge of the starting block with their hands(N. Z. Bulgakova et al., 2001); (N. Z Bulgakova, Salomatin, \& Zhuravik, 1996) mechanics of the start (Bazhanov \& Melkonov, 1979), initial posture of the swimmer on the starting block during the execution of the different variants of start with edge grasping and the traditional variant and the execution phases of the start from the starting block (N. Z Bulgakova et al., 1996), execution of the “tucked" start (Men'shutkina, Silant'eva, \& Mosunov, 1989), (Men'shutkina \& Kozlov, 1987), variants of the start with legs bending in coxo-femoral joint and in tucked position (Schramm, 1987), quality of the jump - spring (Parfenov et al., 1990), integrity of the physical skills and coordinative capacities (Nazarenko, 2000), insufficient knowledge of the start used in light athletics (Rahmanova, 1987), (N. N. Chaplinskij, 1981; N. N. Chaplinskij, 1981), trajectory of the flight and particularities of water load after the start (N. Z. Bulgakova et al., 2001), importance of the start in the relay phase of the swimming relay race (Vajcovskij, 1981) and review during the warm-up phase - of partner's spatial orientation at arrival (Mosunov, 1981).

The analysis of the test events results of the subjects under study highlight the level of the their physical training (mean; \pm S.E.M.), concerning the abdominal strength with a value of $25.75 ; \pm 0.96$ number of reps in 30 sec, arms strength $-22.08 ; \pm 1.14$ number of reps in $30 \mathrm{sec}$, legs strength $23.75 ; \pm 0.73$ number of reps in $30 \mathrm{sec}$ and performance achieved in freestyle $-42.80 ; \pm 1.96 \mathrm{sec}$, with a moderate homogeneity in all cases (table 1).

The results of the anthropometric and biomechanical indicators required by the analysis of standing start technique(mean; \pm S.E.M.) point out the data of the height anthropometric measurements with a value of $1.78 ; \pm 0.02 \mathrm{~m}$ and the weight anthropometric measurements - with 69.50; $\pm 2.35 \mathrm{~kg}$; inertia of rotation (IR, $\mathrm{kg}^{\bullet} \mathrm{m}^{2}$ ) specific to the movement of translation with rotation around GCG $-27.68 ; \pm 1.37 \mathrm{~kg}^{\bullet} \mathrm{m}^{2}$ and a poor homogeneity $(17.15 \%)$; radius of body segments movement $(\mathrm{RM}, \mathrm{m})$ foot $0.82 ; \pm 0.03 \mathrm{~m}$, shoulder $-0.511 ; \pm 0.01 \mathrm{~m}$, palm $-0.716 ; \pm 0.03 \mathrm{~m}$, in the other cases the homogeneity is moderate (table 2).

The analysis of the angular characteristics of the key elements of standing start execution (mean; \pm S.E.M.) highlights the following elements: in the preparatory phase, launching posture (start) - LP the angle between shank and hip is equal to $127 ; \pm 4.28$ degrees and the angle between hip and torso $-62 ; \pm 7.41$ degrees; in the basic phase regarding the multiplication of posture (MP) the angle between hip and torso $-125 ; \pm 5.44$ degrees and the angle between torso and arm - 143.92; \pm 4.74 degrees; in final phase concluding posture (CP) for diving into water -36.92 ; \pm 2.28 degrees, with 
moderate homogeneity excepting the angle between hip and torso in LP $(41.41 \%)$ and CP $(21.37 \%)$ - a poor even inexistent homogeneity, which confirms that the subjects are mastering different starting postures (variants) with different angles of diving into water as result of the erroneous execution of the previous stages (table 3).

The analysis of the spatial characteristics of the standing start execution shows the GCG trajectory (mean; \pm S.E.M.) and exemplifies the individual values of the subject stud4 (fig.3) as follows: in LP launching posture, $\mathrm{Xm}$ has a mean of $0.159 ; \pm 0.14 \mathrm{~m}$ and $\mathrm{Ym}-0.753 ; \pm 0.06 \mathrm{~m}$; in MP - flight phase, $\mathrm{Xm}-0.958 ; \pm 0.09 \mathrm{~m}$ and $\mathrm{Ym}-0.554 ; \pm 0.06 \mathrm{~m}$ ( flight length and height); in $\mathrm{CP}$ - concluding posture - entering the water, $\mathrm{Xm}-1.509$; $\pm 0.08 \mathrm{~m}$ and $\mathrm{Ym}-0.07 ; \pm 0.65 \mathrm{~m}$. All values are related to the origin of the starting block according to the subjects' heels in launching posture.

The analysis of the kinematic characteristics of the standing start in terms of angular velocity of body segments related to GCG (mean; \pm S.E.M.) and the exemplification of the individual values of the subject stud4 (fig.4) highlight that the foot in LP has values of $-1.717 ; \pm 0.28 \mathrm{rad} / \mathrm{s}$, in MP - ($11.887) ; \pm 0.93 \mathrm{rad} / \mathrm{s}$ and in $\mathrm{CP}-(-13.375) ; \pm 1.37 \mathrm{rad} / \mathrm{s}$; the shoulder in LP - (5.164); $\pm 1.21 \mathrm{rad} / \mathrm{s}$, in MP - (-1.629); $\pm 0.71 \mathrm{rad} / \mathrm{s}$ and in $\mathrm{CP}-(-1.084)$; $\pm 0.52 \mathrm{rad} / \mathrm{s}$; the $\mathrm{arm}(\mathrm{palm})-(-1.865) ; \pm 0.73 \mathrm{rad} / \mathrm{s}$, in $\mathrm{MP}-0.253 ; \pm 0.52$ and in $\mathrm{CP}-2.69 ; \pm 0.58 \mathrm{rad} / \mathrm{s}$.

The analysis of the dynamic characteristics of the standing start as for the resultant of the displacement force of GCG (mean; \pm S.E.M.) and the exemplification of the individual values of the subject stud4 (fig.5) highlight in $\mathrm{LP}$ the values of $-1998.58 ; \pm 289.6 \mathrm{~N}$, in $\mathrm{MP}-6327.5 ; \pm 500.9 \mathrm{~N}$ and in CP $-5123.3 ; \pm 676.14 \mathrm{~N}$.

The correlative analysis was made by means of Pearson's parametric linear correlation coefficient which highlights strong connections at $\mathrm{p}<0.01$ between the development of arms force and the angle of entering the water in the concluding posture (CP), $\mathrm{r}=-.742$ and between performance (sec) and the hip-torso angle in the flight phase- the body posture multiplication (MP) at the maximum height of GCG, $r=.734$; strong connections at $\mathrm{p}<0.05$ between the level of abdominal force and the angle of entering the water in the concluding posture (CP), $\mathrm{r}=-.637$ while the connections between the other indicators are weak which warns us that improvements are needed both at the level of physical training and at the level of learning the key elements of the start technique in swimming.

The biomechanical analysis of the start executed by the studied subjects, using the video computerized method, in conformity with the results of the linear correlative analysis, allowed to create a modern learning 
program meant to improve the launching posture (LP), to correct the body posture (MP) during flight phase and to optimize the angle of body posture (CP) at the moment of entering the water.

The effectiveness of using the computerized video technique for learning how to make the start in swimming races in the case of the students under study consists in developing an algorithmic program that takes into account the results of the biomechanical characteristics of sports technique key elements and the level of physical training. The comparative analysis will be carried out based on the evaluation performed in the final tests by the end of the $2^{\text {nd }}$ semester, in June 2018. The results will be published in another study.

\section{Conclusions}

The results of this paper prove that the students-subjects of the research developed their muscle strength of arms, abdomen and legs.

The video computerized method used in this research identifies and highlights the kinematic and dynamic characteristics of sports technique key elements of the swimming start, in terms of launching posture, multiplication of body posture (flying through the air) and concluding body posture (entering the water).

The application of the computerized video method in learning the swim start by the higher education students in accordance with their physical training level showed the kinematic and dynamic characteristics of sports technique key elements required for a more effective development of the modern didactical programs of learning and improving the movement in aquatic environment in the chosen swimming styles. Thus the hypothesis proposed for this paper was confirmed.

\section{Acknowledgements}

We are grateful to the second-year - series no. 2 students of the academic year 2017-2018, of the Faculty of General Medicine, in the 9th Department - Medical Recovery, discipline of Physical Education and Sport, from "Carol Davila" University of Medicine and Pharmacy of Bucharest, for their agreement to participate in the study conducted.

We specify that this paper is part of a wider research on the learning of swimming by the students of other faculties than the physical education ones. Other papers included in this project: "Swimming Lesson in Physical Education and Sport Discipline for First-Year Students in the Higher Education of other Profiles” - published previously and „Learning of 
Breaststroke Swimming Style at Physical Education and Sport Subject in the Higher Education of other Profiles" - in course of publication.

I hereby declare under my own responsibility that the subjects participating in the research have been informed of the voluntary nature of participation in the research, of the understanding of the information received and of the understanding that withdrawal can be done at any time, without any negative consequences on the participant.

The research respected the ethical standards of the research, the participants / the next of kin of the participants gave their consent to take part in the research.

\section{References}

Bazhanov, V. V., \& Melkonov, A. A. (1979). Review of the Building of Different Training Machines for Sports Swimming. Swimming (2 ed.). Moscova

Boloban, V. N. (2013). Regulation of athlete's body posture. Kiev: Olympic Literature.

Bulgakova, N. Z., Afanas'ev, V. Z., Makarenko, L. P., Morozov, S. N., Popov, O. I., \& Chebotareva, I. V. (2001). Swimming: Textbook for Institutions. Moscow.

Bulgakova, N. Z., Salomatin, V. R., \& Zhuravik, A. (1996). Effect of Rapid Training and Systematization of Special Training Exercises depending on the Development Level of the Aerobic and Anaerobic Abilities in Elite Swimmers. Theory and Practice of Physical Culture, 1.

Chaplinskij, N. N. (1981). Analysis of Modern Variants Technique of the Launching Start in Swimming and Processing of the Improvement Trends. Moscow.

Chaplinskij, N. N. (1981). Improvement of Launching Start Technique/ Swimming. Moscow.

Espinosa, H. G., Nordsborg, N., \& Thiel, D. V. (2015). Front crawl swimming analysis using accelerometers: A preliminary comparison between pool and flume. Paper presented at the 7th Asia-Pacific Congress on Sports Technology, APCST 2015.

Ganchar, I. (2006). Methods to Teach the Swimming: Technologies of Learning and Improvement. Odessa: Druk Publishing House

Hudson, C. (2014). Inter-analyst variability in swimming competition analysis. . Paper presented at the The 2014 conference of the International Sports Engineering Association.

Hunea, I., Damian, S. I., David, S., Diac, M. M., Iliescu, D. B., \& Ciocoiu, M. (2017). Brief Literature Review on the Mechanisms Involved in Producing Axial Difussion Injury. Brain-broad research in artificial 
intelligence and neuroscience Broad Research in Artificial Intelligence and Neuroscience, 8(4), 91-98.

Ionescu, C. L. (2009). [Caracteristici generale actuale ale disciplinei educatie fizica si sport in învatamantul superior de neprofil ].

Langholza, J. B., Westmana, G., \& Karlsteen, M. (2016). Musculoskeletal modeling in sports - evaluation of different software tools with focus on swimming. Paper presented at the Physical Education and Sport Department. , Bucharest Academy of Economic Studies.

Lupu, E. (2009). Evaluarea calitatilor motrice ale studentilor în universitatile de neprofil Paper presented at the International Scientific Conference. , Galati.

Marinescu, G., \& Balan, V. (2007). Studiu privind eficienta mijloacelor specifice pentru imbunatatirea tehnicii de inot Paper presented at the International Session of Scientific Communications, Bucharest.

Men'shutkina, T. G., \& Kozlov, A. V. (1987). Modern Representations of the Technique Used in Swimming Starts and Turns; Means of Improvement: Educational Book: Saint Petersburg.

Men'shutkina, T. G., Silant'eva, E. I., \& Mosunov, D. F. (1989). Technique of the Start and Turns in Sports Swimming: Lesson. Leningrad.

Mosunov, D. F. (1981). [Technical Bases of Swimming / Lesson: Refresher Course Leningrad: RTP GDOIFK].

Nakashima, M., \& Tsunoda, Y. (2015). Improvement of crawl stroke for the swimming humanoid robot to establish an experimental platform for swimming research. 7th Asia-Pacific Congress on Sports Technology. Procedia Engineering, 112, 517-521.

Nazarenko, L. D. (2000). Spring - Motor-Coordinative Skill. 28-32.

Nordsborg, N. B., Espinosa, H. G., David, V., \& Thiel, D. V. (2014).

Estimating energy expenditure during front crawl swimming using accelerometers. The 2014 conference of the International Sports Engineering Association. Procedia Engineering, 72, 132-137.

Nyvandi, R. A. (1963). Methods to Determine the Launching Start Efficiency and to Monitor the Opportunity of the First Swimming Movements): self-account of the thesis of candidate in pedagogical sciences. . Estonia, Tartu.

Parfenov, V. A., Pasichnichenko, V. A., Ivanchenko, E. I., \& Parfenova, L. V. (1990). Preparation of the Start in Swimmers. Methods Guide: Minsk.

Platonov, V. N., Absaljamov, T. M., Bulatova, M. M., \& Bulgakova, N. Z. (2000). [Swimming: Textbook for Students of the Higher Education Institutions of Physical Education and Sport].

Polevoj, G. F., \& Ruvinskij, L. I. (1972). [The Start - Basic Part of Swimmers' Training. Swimming]. 
Potop, V. (2015). Bases of macro-methods for sports exercises learning - material from Women's Artistic Gymnastics. Monograph. Kiew Education Literature Center.

Rahmanova, A. M. (1987). New Elements in Swimming Start Technique: Briefing. Moscow.

Schramm, E. (1987). Sportschwimmen. Hochschullerbuch. . Berlin.

Sima, E. D. (2011). Inotul in lectia de educatie fizica a studentilor din Universitatea de Medicina si farmacie. Bucharest: Carol Davila: University Publishing House.

Urichianu-Toma, S. (2003). Educatia fizica generala si specifica a studentilor militari Bucharest: Publishing House of Military Technical Academy.

Urichianu-Toma, S. (2004). Inotul la copii, adolescenti si tineri Bucharest: Publishing House of Military Technical Academy.

Vajcovskij, S. M. (1981). Substitutes of Relay Race. Swimming.

Voinea, A., Iacobini, A., \& Iacobini, P. (2013). Educatia fizica si sportul in viata studentilor Bucharest: ASE Publishing House.

Webb, A. P., Taunton, D. J., Hudson, D. A., Forrester, A. I. J., \& Turnock, S. R. (2014). The effect of swimsuit resistance on freestyle swimming race time. The 2014 conference of the International Sports Engineering Association. Procedia Engineering, 72, 709-714. 